To Maega | JurnalPengabdianMasyarakat

Bulan-Tahun, Vol.4, No.3, hal, 304-315

$\operatorname{ISSN}(P): 2622-6332 ; \operatorname{ISSN}(E): 2622-6340$

http://www.ojs.unanda.ac.id/index.php/tomaega

\title{
Pelatihan Drama Bagi Siswa SMP Negeri 1 Songgom
}

\author{
Robert Rizki Yono ${ }^{*}$, Atikah Mumpuni², Agyztia Permana ${ }^{3}$, Ubaedillah ${ }^{4}$ \\ 1,4Program Studi Pendidikan Bahasa dan sastra Indonesia, Fakultas Keguruan dan Ilmu \\ Pendidikan, Universitas Muhadi Setiabudi \\ ${ }^{2}$ Program Studi Pendidikan Guru Sekolah Dasar, Fakultas Keguruan dan IImu Pendidikan, \\ Universitas Muhadi Setiabudi \\ ${ }^{3}$ Program Studi Teknik Informatika, Fakultas Teknik, Universitas Muhadi Setiabudi \\ *Correspondent Email: robertriskiyono@gmail.com
}

Article History:

Received: 04-09-2021; Received in Revised: 22-09-2021; Accepted: 02-10-2021

DOI: http://dx.doi.org/10.35914/tomaega.v4i3.846

\begin{abstract}
Abstrak
Siswa SMP Negeri 1 Songgom tergolong aktif. Tetapi, keaktifan siswa belum terakomodir dengan baik. Meskipun terdapat beberapa ekstrakulikuler, belum sepenuhnya menampung minat siswa. Khususya ekstrakulikuler drama tidak ada. Faktor tidak adanya teater/drama karena minimnya tenaga pengajar bahasa Indonesia. Lanjut, terkait dengan keaktifan anak, khususnya di kelas VII perlu didalami terlebih dahulu. Didalami dalam arti diselidiki, keaktifan tersebut mengarah pada bakat kemampuan berakting untuk mendukung kegiatan drama, atau mengarah pada kegiatan lain. Selain itu, belum pernah dilaksanakan pelatihan drama. Oleh karena itu, perlu dilakukannyakegiatan sosialisasi dan pelatihan drama bagi siswa SMP N 1 Songgom. Sasaran dan luarannya adalah tersalurnya minat dan bakat siswa serta memiliki kemampuan dasar berdrama. Tahapan kegiatan meliputi sosialisasi, pelatihan, dan evaluasi. Metodenya berupa ceramah, diskusi, dan demonstrasi. Tahap implementasi meliputi pemberian materi terkaitkonsep dasar,unsur-unsur dan latihan dasar berdrama serta praktik.Secara umum, peserta menunjukan hasil yang cukup baik. Hal inimembantu siswa meningkatkan pemahaman tentang drama dan mengetahuipotensi/bakatnya. Hasil Kesimpulan dari kegiatan ini kongkrit bermanfaat bagi para siswa dalam memahami konsep dasar dramadan dapat mempengaruhi minat siswa dalam melaksanakan kegiatan drama. Disarankan kegiatan ini dilanjutkan untuk berlatih menulis naskah.
\end{abstract}

Kata Kunci: Pelatihan, Drama, Siswa SMP

\section{Abstract}

State Junior High School Student 1 Songgom is classified as active. However, the activeness of students has not been well accommodated. Although there are some extracurriculars, it has not fully accommodated the interests of students. Especially extracurricular dramas do not exist. The factor of the absence of theater / drama due to the lack of Indonesian language teaching staff. Furthermore, related to the activeness of children, especially in class VII need to be explored first. In the sense of being investigated, such liveliness leads to the talent of acting ability to support drama activities, or leads to other activities. In addition, there has never been drama training. Therefore, it is necessary to conduct socialization and drama training for junior high school students $N 1$ Songgom. The target and externality is the channeling of students' interests and talents and having basic ability to preach. The stages of activities include socialization, training, and evaluation. The methods are lectures, discussions, and 
demonstrations. The implementation phase includes the provision of material on basic concepts, elements and basic practice of rhythm and practice. In general, participants showed quite good results. This helps students improve their understanding of drama and know their potential/ talents. The conclusion of this activity is concretely beneficial for the students in understanding the basic concepts of drama and can affect the interest of students in carrying out drama activities. It is recommended that this activity be continued to practice writing the script.

Key Word:Training, Drama, Junior High School Student

\section{Pendahuluan}

SMP Negeri 1 Songgom adalah sekolah yang terletak di Desa Wanacala, Kabupaten Brebes. Sekolah tersebut beralamat di Jalan Raya Wanacala Rt $07 \mathrm{Rw}$ 02, Songgom, Dukuh I, Songgom Lor, Kabupaten Brebes, Jawa Tengah. Sebagai salah satu sekolah negeri di desa Wanacala, tentu sekolah ini dapat dikatakan sebagai sekolah 'gemuk' karena memiliki banyak siswa. Sekolah tersebut, memiliki jumlah guru 35 orang dengan 16 rombel belajar. Adapun rincian jumlah peserta didik yaitu 234 laki-laki dan 216 perempuan (Sekolah Kita, n.d.).

Siswa-siswa di SMP Negeri 1 Songgom tergolong siswa-siswa yang aktif. Akan tetapi, keaktifan siswa-siswa tersebut belum terakomodir dengan baik. Oleh sebab itu, banyak bakat-bakat siswa yang semestinya dapat berkembang, menjadi tidak berkembang. Meskipun di sekolah sudah ada ekstrakulikuler, menurutbeberapa guru, tetap belum dapat menampung minat bakat siswa yang begitu banyak dengan optimal. Menurut (Marantika, 2014)dikarenakan belum siap menerima perubahan paradigma baru pada pembelajaran sastra dan terpengaruh dengan kondisi pembelajaran sastra yang lama yang berdampak pada pembelajaran sastra sekarang ini menjadi biasa saja dan kurang menarik.

Di sekolah yang telah terakreditasi B tersebut, terdapat beberapa ekstrakurikuler. Secara garis besar, ekstrakurikuler tersebut terdiri dari wajib dan pilihan. Ekstrakurikuler wajib contohnya yaitu pramuka dan ekstrakurikuler tambahan ada beberapa pilihan contohnya yaitu PMR (Palang Merah Remaja), beberapa ekstra yang berbau olah raga, dan drumband. Sayangnya tidak ada ekstrakurikuler yang berkaitan dengan sastra, seperti teater.

Padahal banyak manfaat yaang didapat siswa dalam pembelajaran drama atau teater, seperti ranah kognitif, afektif, dan psikomotorik. Pertama, mendorong munculnya apresiasi drama pada siswa. Kedua, membentuk karakter, sikap, dan emotif pada siswa. Ketiga, siswa dapat mengelaborasi untuk menilai dan memaknai secara untuh terhadap teks drama yang dibacanya (Marantika, 2014). Berdasarkan hasil observasi awal yang telah dilakukan sebelum dilaksanakannya kegiatan pengabdian masyarakat, siswa-siswi di sekolah tersebut tergolong siswa yang aktif. Aktif dalam hal keterampilan berbicaranya, juga aktif dalam hal gerak tubuh. Hasil observasi tersebut diperkuat oleh guru Bahasa Indonesia yang mengaitkan keaktifan siswa tersebut dengan kecenderungan gaya belajar 

2021

kinestetik. Secara khusus, Urip Triyono, S.S., MM.Pd selaku pembina OSIS SMP Negeri 1 Songgom mengemukakan, belum diadakannya ekstrakulikuler teater atau drama karena belum adanya tenaga pengajar yang mendukung. Selama ini menurutnya, guru bahasa Indonesia hanya terdiri dari dua orang yang sudah memiliki jam mengajar yang cukup padat, sehingga tidak memungkinkan mendampingi anak-anak dalam ektrakulikuler teater. Hal ini senada dengan pendapat (Soleh dan Huda, 2013) bahwa kesulitan dalam proses pembelajaran drama di sekolah diantaranya yaitu kekurangan pelatih atau pengajar

Pembina OSIS tersebut juga mengemukakan, terkait dengan keaktifan anak, khususnya di kelas VII perlu didalami terlebih dahulu. Didalami dalam arti diselidiki, keaktifan tersebut mengarah pada bakat kemampuan berakting untuk mendukung kegiatan drama, atau mengarah pada kegiatan yang lainnya. Selain itu, di SMP Negeri 1 Songgom juga belum pernah dilaksanakan pelatihan dasar-dasar drama, sehingga pihak sekolah belum bisa memastikan terkait keaktifan siswa tersebut mengarah pada drama atau bukan.

Berdasarkan pemaparan di atas, maka permasalahan mitra dapat diuraikan yang pertama, siswa-siswi SMP Negeri 1 Songgom, tergolong siswa aktif. Akan tetapi keaktifan siswa tersebut belum sepenuhnya diarahkan untuk mendukung minat dan bakat siswa terkait dengan drama. Kedua, selain belum adanya ekstrakulikuler teater/drama, di SMP Negeri 1 Songgom juga belum pernah dilaksanakan pelatihan dasar-dasar drama, sehingga belum dapat menggali minat dan bakat siswa dalam bidang drama.

Target dari kegiatan pengabdian kepada masyarakat ini adalah keaktifan yang dimiliki oleh siswa di SMP Negeri 1 Songgom dapat tersalurkan pada minat dan bakatnya. Selain itu, melalui pelatihan yang dilakukan juga diharapkan membuat siswa dapat memiliki kemampuan dasar drama sebagai modal awaldalam mengasah minat dibidang drama/teater. Lanjut menurut (Ragnarsdóttir \& Porkelsdóttir, 2012) bahwa berdrama dapat mengembangkan keterampilan berkomunikasi para siswa.

Luaran kegiatan pengabdian kepada masyarakat ini diharapkan siswa dapat melakukan kegiatan drama dengan menerapkan dasar-dasar drama yangsebelumnya telah dipelajari dan dipraktikkan dengan percaya diri dan artikel yang dipublikasikanpada jurnal nasional terakreditasi.

\section{Metode}

Pengabdian kepada masyarakat ini dilaksanakan pada bulan September di SMP Negeri 1 Songgom, Desa Wanacala, Kecamatan Songgom, Kabupaten Brebes tahun 2019. Peserta kegiatan pengabdian masyarakat ini adalah siswa kelas VII ( 34 Siswa). Beberapa tahapan serangkaian kegiatan pengabdian kepada masyarakat meliputi:

1. Sosialisasi kegiatan pengabdian masyarakat tentang pelatihan drama bagi license (https://creativecommons.org/licenses/by-sa/4.0/). 
[ 307 ] Robert Rizki Yono, dkk/ To Maega : Jurnal Pengabdian Masyarakat, Vol.4; No.3; Oktober, 2021

siswa kelas VII SMP Negeri 1 Songgom. Sosialisasi dilakukan siswa kelas VII di SMP Negeri 1 Songgom mengenai manfaat berdrama karena pentingnya berdrama diantaranya untuk mendalami berbagai persoalan manusia dalam naskah yang dibawakannya dan dapat memahami manusia lain dengan lebih baik dibandingkan sebelumnya.

2. Pelatihan drama: Pelatihan ini diikuti oleh siswa kelas VII SMP Negeri 1 Songgom. Materi pelatihan ini yaitu definisi drama, manfaat berlatih drama, unsur-unsur drama, dan langkah-langkah bermain drama menurut (memilih naskah, berlatih pertunjukan, dan melaksanakan pementasan) dengan metode pelatihan ceramah, diskusi, demonstrasi dan praktik. Dalam pertunjukan menggunakan pendapat Brocket.

3. Monitoring dan evaluasi: Semua kegiatan yang dilaksanakan itu dimonitor yang diantaranaya menggunakan daftar hadir dan didokumentasikan yang selanjutnya dilakukannya evaluasi untuk ditindaklanjuti. Peningkatan pengetahuan dievaluasi menggunakan indikator keberhasilan penilaian selama kegiatan pelatihan berlangsung. Indikator keberhasilan dalam kegiatan pelatihan sebagai berikut.

a. Mampu mengikuti kegiatan pelatihan dengan antusias.

b. Mampu menguasai kemampuan dasar berdrama dan menerapkan teknik berperan Oscar Brocket dalam praktik berdrama.

\section{Hasil dan Pembahasan}

Kegiatan Pengabdian kepada Masyarakat (PKM) dari Universitas Muhadi Setiabudi terlaksana dengan lancar. Diantaranya kegiatan PKM yang terlaksana yaitu pelatihan mengenai drama bagi siswa SMP. Kegiatan Pelatihan ini diikuti oleh siswa kelas VII SMP N 1 Songgom kabupaten Brebes, Jawa Tengah sebanyak 34 siswa. Materi yang disampaikan pada pelatihan ini yaitu konsep dasar berdrama, manfaat berlatih drama, unsur-unsur drama, dan langkah-langkah bermain drama (memilih naskah, berlatih pertunjukan, dan melaksanakan pementasan) dengan metode pelatihan ceramah, diskusi, demonstrasi dan praktik.

\section{Sosialisasi Berlatih Drama}

Sosialisasi kegiatan pengabdian masyarakat tentang pelatihan drama bagi siswa kelas VII SMP Negeri 1 Songgom.Sosialisasidilakukankepadasiswa kelas VII di SMP Negeri 1 Songgom. materi diberikan berbentuk ceramah dan tanya jawab mengenai berdrama, khususnya manfaat berlatih drama. 


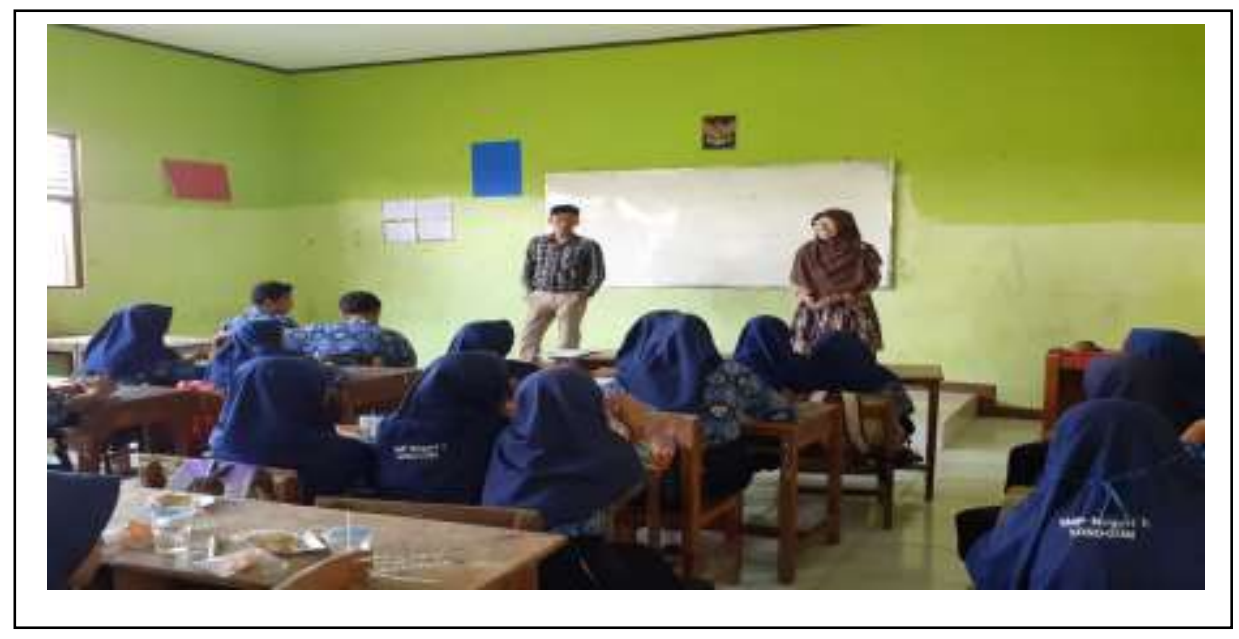

Gambar 1. Sosialisasi berlatih drama

Peningkatan pengetahuan pra dan pasca materi diberikan dapat dilihat pada gambar berikut ini.

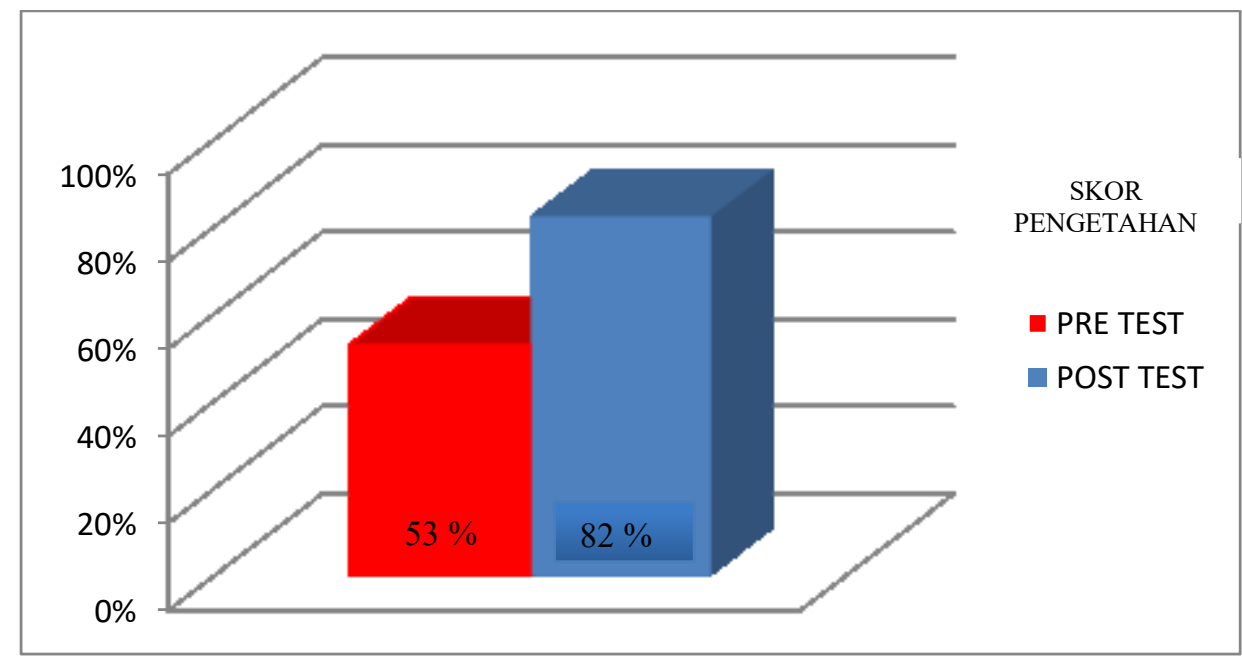

Gambar 2. Skor pengetahuan siswa pra dan pasca pemberian materi

Berdasarkan gambar di atas menunjukan adanya peningkatan pengetahuan siswa pra dan pasca pemberian materi dari $53 \%$ menjadi $82 \%$. Hal ini selaras dengan penelitian (Gafari, 2015) bahwa untuk model demonstrasi dapat meningkatkan keterampilan berdrama pada siswa. Hal ini diperkuat oleh penelitian (Baihaqi, 2016) bahwa kemampuan siswa dalam berdrama mengalami peningkatan setelah mengikuti pembelajaran bermain drama dengan model tertentu.

Pemberian informasi yang bersifat edukatif atau mendidik akan meningkatkan pemahaman pribadi terhadap objek tertentu, sehingga dapat mengubah cara pandangnya. Dengan demikian bahwa dilaksanakannya pelatihan dapat memberikan pengetahuan kepada siswa. Hal ini selaras dengan pendapat (Lastaria \& Azzakiyah, 2020) bahwa tim pengabdian sangat membantu siswa-siswi dalam memperoleh pengetahuan. 

2021

\section{Pelatihan Drama Bagi Siswa Kelas VII SMP Negeri 1 Songgom}

Kegiatan pelatihan ini dilakukan selama dua hari di SMP Negeri 1 Songgom diikuti oleh siswa kelas VII. Metode yang dilakukan adalah ceramah, diskusi, demonstrasi, praktek dan pendampingan siswa. Materi dalam pelatihan ini yaitu definisi drama, manfaat berlatih drama, unsur-unsur drama, dan langkah-langkah bermain drama (memilih naskah, berlatih pertunjukan, dan melaksanakan pementasan)

Kegiatan pelatihan ini dibuka oleh Robert Rizki Yono, M.Pd. selaku ketuatimpengabdian masyarakatuntuk memberikan sebuah penjelasan terkait kegiatan yang hendakdilaksanakan danmanfaatnya bagi siswa,selanjutnya dengan kegiatan demonstrasi olehtim yang terdiri dari Atikah Mumpuni, M.Pd., Agyztia Permana, M.Kom, dan Ubaedillah, M.Pd .

Kegiatan pelatihan memanfaatkan media pembelajaran berupa power point yang ditampilkan kepada siswa yang hadir.Isi power point tersebut berkaitan dengan materi definisi drama, dan unsur-unsur drama, khususnya langkah-langkah bermain drama yang digunakan pada saat demonstrasi agar dapat diimplementasikanoleh siswa.

Siswa-siswi berantusias pada saat mengikuti kegiatan pelatihan ini. Awalnya, pelatihan diikuti oleh sekitar dua puluh siswa, suasana sangat kondusif dan mudah untuk diarahkan. Akan tetapi, setengah jam kemudian ada tambahanpeserta pelatihan lagi, hal ini membuat kegiatan pelatian menjadi kurang kondusif. Senada dengan pendapat (Ibrahim et al., 2021) bahwa peserta didik belum kondusif tetapi dengan berjalannya waktu akan berubah menjadi kondusif. Namun tim pengabdian masyarakat mampu membalikan situasi menjadi kembali kondusif. Siswa sangat berantusias dalam mengikuti kegiatan yang ditandai dengan keaktifan para siswa dalam bertanya selama kegiatan demonstrasi. Hal ini selaras dengan apa yang dikatakan oleh (Suprajitno, 2017) bahwa berbagai usaha yang pernah dilakukan, seperti berdiskusi dengan para fasilitator yang membantu penelitian ini merupakan cara untuk membangkitkan antusiasme partisipan, dan dapat membangkitkan minat mereka, serta berusaha untuk membuat mereka lebih merasa nyaman dan tidak merasa terbebani dengan proyek seperti ini. Seiring dengan berjalannya waktu, antusias partisipan pun bertumbuh. Dengan kata lain siswa bersikap positif terhadap pelaksanaan pelatihan ini. Selaras dengan pendapat (Ngoch \& Huan, 2017) bahwa siswa bersikap positif terhadap pelaksanaan kegiatan berdrama.

Dalam kegiatan demonstrasi, tim pengabdian menggunakan media power point sehingga membantu siswa untuk lebih memahami materi yang disampaikan. Sebagaimana yang dikatakan oleh Wahyudian dalam (Hadi et al., 2020) bahwa agar pembelajaran berjalan menarik dan efektif, maka seorang pendidik menggunakan berbagai macam media pembelajaran yang berbasis ICT. 

2021

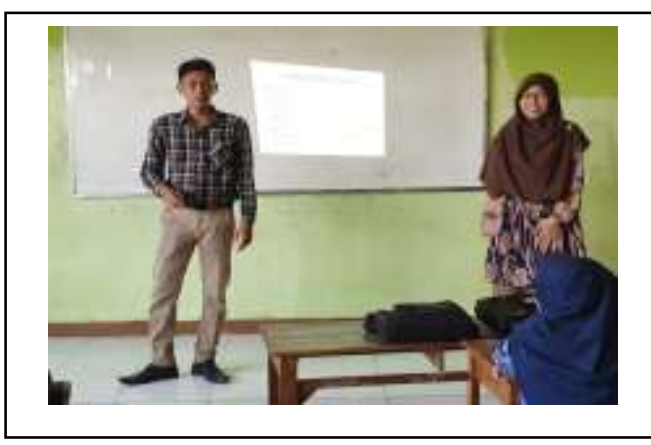

Gambar 3. Demonstrasi bermain drama

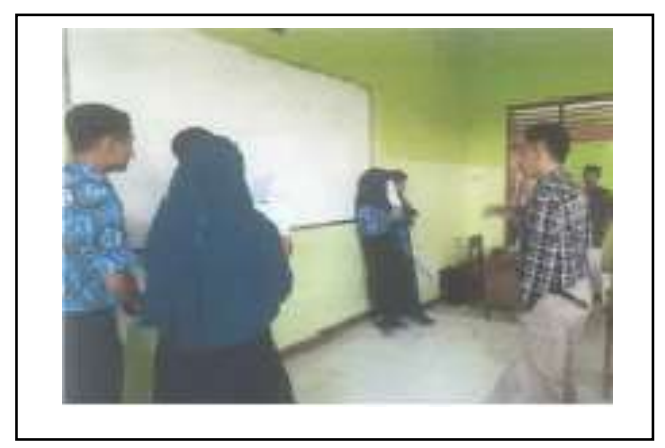

Gambar 4. Evaluasi hasil praktik siswa

Setelah kegiatan demonstrasi selesai, dilanjutkan dengan dipraktikan secara langsung oleh siswayang didampingi tim pengabdian masyarakat.Pementasan dilaksanakan di dalam kelas dengan satu naskah drama pendek oleh semua siswa yang dibagi beberapa kelompok. Kelompok yang belum mendapatkan giliran pementasan, diajak untuk mengamati. Pementasan kurang lebih berdurasi 15 Menit sampai 20 menit. langkah-langkah singkatpentas drama adalah sebagai berikut.

Kegiatan ini menghasilkan pengetahuan baru bagi siswa tentang drama, khususnya teknik berperan drama Oscar Brocket. Siswa menyimak materi drama yang disampaikan tim pengabdian masyarakat karena merasa penasaran dengan materi dan media yang digunakan serta antusias dalam mempraktikan teknik berperan Brocket. Siswa merasakan manfaat dari penyampaian materi dan praktik berperan menggunakan teknik Brocket. Siswa sudah dapat menghayati karakter tokoh, ekspresi, pengucapan, dan ritme yang ada di dalam naskah. Selaras dengan hasil penelitian (Andriani, 2013) bahwa berlatih bermain peran atau drama dapat meningkatkan kemampuan memerankan tokoh drama. Penguasaan panggung dan konsentrasi siswa masih perlu ditingkatkan lagi. Secara umum, peserta menunjukan hasil yang cukup baik. Hal ini membantu siswa meningkatkan pemahaman tentang drama dan mengetahui potensi/bakatnya. Senanda dengan (Moeljadi. \& Dkk, 2016) bahwa untuk mengembangkan atau meningkatkan potensi yang dimilikinya atau yang disukai, karena manusia membutuhkan pendidikan dalam arti luas untuk dapat menumbuhkembangkan potensi yang ada pada dirinya. Ketercapaian tujuan pelaksanaan pelatihan drama ditunjukan melalui indikator keberhasilan dalam penilaian selama kegiatan pelatihan berlansung, yaitu.

1. Mampu mengikuti kegiatan pelatihan dengan antusias.

2. Mampu menguasai kemampuan dasar berdrama dan menerapkan teknik berperan Oscar Brocket dalam praktik berdram.

Berikut contoh naskah drama yang dipraktikan oleh siswa berjudul "Sabar tetap sabar".

Babak 1

Narator:

"Pagi yang cerah ketika sang fajar melambaikan tangannya yang disertai bunyi 
ayam berkokok, ada sebuah keluarga kecil yang dikepalai oleh seorang yang bernama Sabar yang ditemani oleh seorang istri yang bernama Nerima yang hanya memiliki seorang putri bernama Kasih. Keluarga Sabar beraktivitas seperti biasayaitu berkumpul untuk menikmati sarapan. Secara tidak sengaja Kasih menjatuhkan nasi yang dibungkus daun".

Sabar:

"Astagfirullah, hati-hati de Kasih."

Kasih:

"Iya Abah, Kasih minta maaf telah menjatuhkan nasi yang sudah Ibu belikan."

Nerima:

"Biarkan Ibu yang membersihkan de." (sambil tersenyum).

Sabar:

"Bagaimana sekolah mu de?"

Kasih:

"Alhamdulillah Bah, lancar tidak ada kendala."

(sambil tersenyum kepada Abah dan Ibu).

Sabar:

"Syukurlah, bagaimana pun de kamu harus sekolah setinggi mungkin agar kamu menjdai orang yang berguna. Kamu tidak boleh minder sama teman kamu karena memang inilah keadaan kita. Kita itu orang susah tetapi ketika kita berusaha dan berdoa pasti Allah akan mempermudah hidup kita."

Kasih:

"Amin yra. Iya Abah, De Kasih akan selalu belajar dan berdoa kepada Allah Swt. agar kelak kasih menjadi orang yang berguna bagi agama, nusa, bangsa, dan keluarga."

Nerima:

"Meskipun kita orang susah, kamu jangan memikirkan tentang biaya sekolah. Tugas kamu itu belajar, biarkan Abah yang bekerja untuk memenuhi kebutuhan kita."

Babak 2

Narator:

Tidak terasa waktu menunjukan pukul 06.30. Mereka mulai mengerjakan tugas dan kewajiban masing-masing. Nerima bersiap pergi ke sekolah, Sabar bersiap ke sawah karena menjadi buruh tani, dan Nerima bersiap ke rumah tetangga karena menjadi buruh cuci. Sambil memakai camping dan membawa cangkul Sabar berpamitan kepada Nerima. Datanglah majikan Sabar yang bernamaSugi Harta untuk mengajar berangkat bersama menuju sawah. Setelah di sawah Sabar mulai mencangkul. Sambil mencangkul sabar menjawab pertanyaan majikannya.

Sugi Harta:

"Bar, bagaimana sekolah anak mu?"

Sabar:

CTo Maega / JurnalPengabdian Masyarakat. This is an open access article under the CC BY-SA 4.0 license (https://creativecommons.org/licenses/by-sa/4.0/). 
[ 312 ] Robert Rizki Yono, dkk/ To Maega : Jurnal Pengabdian Masyarakat, Vol.4; No.3; Oktober, 2021

"Alhamdulillah lancar bos, malah kemaren mendapat nilai yang baik."

Sugi harta:

"Oh bagus ya Bar, beruntunglah kamu punya anak cerdas dan baik."

(sambil menggeleng-gelengkan kepala karena merasa heran dengan kebahagiaan keluarga sabar).

Sabar:

"Alhamdulillah bos, selain itu saya juga bersyukur mempunyai bos yang baik" (sambil tertawa terbahak-bahak).

Sugi Harta:

"Ah Kamu bisa saja bar. Jika kamu butuh uang untuk biaya pendidikan anakmu, jangan sungkan menghubungi saya karena kamu sudah begitu lama ikut bekerja di saya. Selain itu kamu orang yang baik"

(Sambil tertawa).

Narator:

"Tepat menjelang senja yang disertai suara mengaji yang berasal dari mushala Sabar pulang menuju rumah ditemani tetesan air hujan yang diiringi bunyi petir. Bagi sabar itu bukan masalah tetapi itu sebuah berkah dari Allah. Sesampainya di rumah Sabar menunaikan ibaha sholat sehabis ia membersihkan tubuhnya yang telah dilumuri lumpur, dibalut keringat, dan dibasuh air hujan."

Babak 3

Narator:

"Keluarga sederhana itu seperti biasa makam malam bersama dengan lauk seadanya. Kasih membuka percakapan disela-sela makam malam yang penuh dengan kehangatan cinta dan kasih sayang”

Kasih:

"Ibu, tadi di sekolah Kasih ditegur Pak Mosi tertaik pembayaran yang sudah telat tiga bulan, kata beliau kalau tidak membayar nanti Kasih tidak boleh mengikuti ujian nasional"

(Sambil menundukan kepala dengan mimik sedih).

Nerima:

"Jika satu minggu lagi bagaima Kesih? Karena Ibu belum ada uang dan Abah pun sawah yang digarap belum panen"

(sambil menitihkan air mata)

Sabar:

"Apakah besok batas pembayaran kamu, tidak boleh satu minggu lagi de?"

Kasih:

"iya Abah, besok paling lambat."

Sabar:

"Ya Allah, mohon ampunilah dosa hamba karena hamba belum mampu untuk mencukupi kebutuhan keluarga hamba dan berikanlah pertolongan untuk hamba untuk mengatasi persoalan ini."

CTo Maega / JurnalPengabdian Masyarakat. This is an open access article under the CC BY-SA 4.0 license (https://creativecommons.org/licenses/by-sa/4.0/). 
[ 313 ] Robert Rizki Yono, dkk/ To Maega : Jurnal Pengabdian Masyarakat, Vol.4; No.3; Oktober, 2021

(ucapnya di dalam hati).

Nerima:

"Begitu kah Kasih, coba nanti setelah makan Ibu ke tetangga untuk meminjam uang."

Kasih:

"Maafkan Kasih ya Abah dan Ibu karena Kasih menjadi beban keluarga, saya tidak berkaca, saya selalu memikirkan diri sendiri untuk menjadi seorang sarjana."

Sabar:

"Tidak apa-apa Kasih, Bapaklah yang belum mampu untuk membiayai mu."

Nerima:

"Jangan begitu Abah, Abah sudah berjuang untuk mencukupi kebutuhan kita dan

Kasih pun sudah belajar dengan baik. Mari kita bersiap untuk sholat Isya dan memohon kepada Allah Swt. agar diberikan jalan keluar."

Kasih:

"Iya ibu, mari Abah dan Ibu, Kasih pamit untuk bersiap sholat Isya."

Narator:

"Ketika keluarga Sabar sedang diselimuti kesedihan, suara tok,tok,tok dari arah pintu berbunyi disertai suara Assalamualaikum. Suara Pak Sugi Harta yang mengetuk pintu itu. Tidak lama kemudian Sabar membukakan pintu dan mempersilakan duduk."

Sugi Harta:

"Terima kasih pak sabar, pertama saya datang untuk silaturrahim dan yang kedua saya tidak mau basa basi, saya ingin melihat putri Bapak yang cerdas itu."

Sabar:

"Tumben Pak Bos, ada angin apa bapak ingin bertemu dengan putri saya. Biasanya bapak ingin bertemu saya?"

(Sambil tersenyum dan meminta wedang kepada istrinya untuk pak Bos).

Sugi Harta:

"Iya nih pak, saya tadi bertemu dengan Cantika keponakan saya yang satu kelas dengan Kasih. Katanya Kasih harus melunasi tunggakan pembayaran sekolah. Sehingga saya langsung ke sini untuk bertemu Kasih.”

Sabar:

"Kasih, ini ada pak Bos inggin bertemu dengan mu!"

(sambil tersenyum bahagia)

Kasih:

"Iya Abah, Kasih segera datang."

Nerima:

"Silakan diminum Abah dan pak Bos."

Sugi Harta:

"Terima kasih Bu Sabar, sudah menyuguhkan wedang dan mempersilakan saya untuk meminumnya."

Kasih:

(CTo Maega / JurnalPengabdian Masyarakat. This is an open access article under the CC BY-SA 4.0 license (https://creativecommons.org/licenses/by-sa/4.0/). 
[ 314 ] Robert Rizki Yono, dkk/ To Maega : Jurnal Pengabdian Masyarakat, Vol.4; No.3; Oktober, 2021

"Ada apa Pak?"

Sugi Harta:

"Iya tadi Cantika bilang ke saya kalau kamu itu ditegur pihak sekolah untuk melunasi biaya pendidikan mu. Jadi saya ke sini, karena saya tahu kalau Bapak mu belum ada uang untuk membayar sebab sawah yang saya berikan ke bapak mu untuk digarap belum panen dan saya sudah bilang ke bapak mu, jika nanti Kasih butuh uang untuk membayar tagihan sekolah, silakan Pak Sabar menghubungi saya. Tapi ya begitulah sikap bapak mu"

(sambil melirik ke pak Sabar dan tertawa terbahak-bahak)

Kasih:

"Alhamdulillah, terima kasih Pak Bos atas bantuannya, iya tadi pagi pas di sekolah Cantika melihat dan mendengar saya ditegur pihak sekolah."

(sambil mencium kedua tangan orang tua nya dan pak Bos dengan mimik wajah yang ceria).

Sabar dan Nerima:

"Alhamdulillah, Terima kasih Pak Bos sudah membantu kami.

(sambil saling tersenyum)

Sugi Harta:

"Bersyukurlah kepada Allah, saya hanya perantara karena rezeki ini pun hanya sekedar titipan jadi saya harus berbagi. Pesan saya kepada Kasih hanya satu yaitu jika kelak Kasih menjadi orang yang sukses, Kasih juga harus melakukaka apa yang saya lakukan. Ya!"

Kasih:

"Iya Pak Bos, semoga Kasih dapat seperti Pak Bos. Sudah kaya, pintar dan baik hati. Amin yra."

(sambil kedua tangan menadah ke atas)

Sugi Harta:

"Ya sudah, ini uangnya saya berikan lebih agar sisanya untuk jajan Kasih. Semoga bermanfaat, sekalian saya izin pulang. Assalamualaikum.

Kasih;

"Terima Kasih Pak Bos, Waallaikum salam Hati-hati di jalan Pak Bos." (sambil menempelkan kedua tangan dan menganggukan kepala)

Sabar dan Nerima:

"Terima kasih Pak Bos, semoga allah membalas kebaikan Pak Bos. Waallaikum salam. ”

(sambil tersenyum dan menempelkan kedua tangan disertai mengaggukan kepala) Narator:

"Begitulah keluarga Pak Sabar, selain sederhana mereka juga sangat ramah. Meskipun dalam keadaan susah mereka yakin akan pertolongan Allah swt. bahwa ada rezeki yang datang tidak terduga asal kita bekerja keras dan berdoa serta menerima apapun yang sudah ditakdirkan Allah Swt. 

2021

\section{Kesimpulan}

Kesimpulan dari kegiatan pelatihan dramabagi siswa kelas VIISMP Negeri 1 Songgom, yaitu. Pertama, Siswa di SMP Negeri 1 Songgom sangat antusias mengikuti kegiatan pelatihan tersebut. Kedua, Drama yang ditulis dan diperankan oleh siswa sangat mempengaruhi minat siswa kelas VII SMP Negeri 1 Songgom dalam melaksanakan kegiatan drama. Berharap agar kegiatan ini terus berlanjut terutama pihak sekolah agar membentuk ekstra kurikuler bermain peran atau drama.

\section{Ucapan Terimakasih}

Tim penulis mengucapkan terima kasih kepada Universitas Muhadi Setiabudi yang telah mendanai pengabdian masyarakat ini dan kepada Jurnal Pengabdian To Maega yang berkenan menerbitkan artikel pengabdian ini.

\section{Daftar Pustaka}

Andriani, N. P. A. R. (2013). Penerapan Model Pembelajaran Bermain Peran (Role Playing) untuk Meningkatkan Keterampilan Siswa Memerankan Tokoh dalam Pementasan Drama Siswa Kelas XI IPB SMA Saraswati Singaraja. Pendidikan Bahasa Dan Sastra Indonesia, 7(1), 1-14.

Baihaqi, I. (2016). Peningkatan Keterampilan Bermain Drama Dengan Metode Role Playing Pada Kelompok Teater Kenes Smpn 4 Yogyakarta. Transformatika, 12(September), 15-28. https://core.ac.uk/download/pdf/228480125.pdf

Gafari, M. O. F. (2015). Peningkatan Keterampilan Bermain Drama Dengan Menggunakan Model Demonstrasi Pada Siswa Kelas Ix Tanjung Bali Tahun Pembelajaran 2014/2015. Jurnal Unimed, 26(4). https://doi.org/DOI: https://doi.org/10.24114/bhs.v26i4.5623

Hadi, F., Syafi'i, A., \& Isgandi, Y. (2020). Pelatihan Penerapan Pembelajaran Daring Interaktif Bagi Guru-Guru SD Al Islam Morowudi, Gresik. To Maega: Jurnal Pengabdian Masyarakat, 3(2), 142. https://doi.org/10.35914/tomaega.v3i2.420

Ibrahim, M., Cahyani, I., \& Sundusiah, S. (2021). Peningkatan Kemampuan Bermain Peran Menggunakan Metode Demonstrasi Berbantuan Multimedia Film. @rtikulasi, 1(1), 48-54. https://ejournal.upi.edu/index.php/JPBSI/article/view/32527

Lastaria, L., \& Azzakiyah, L. F. (2020). Nilai Moral dan Budi Pekerti Melalui Pembelajaran Islam. To Maega | Jurnal Pengabdian Masyarakat, 3(1), 1. https://doi.org/10.35914/tomaega.v3i1.276

Marantika, J. E. R. (2014). Drama Dalam Pembelajaran Bahasa dan Sastra. Tahuri, 11(2), 92-102.

https://ejournal.unpatti.ac.id/ppr_iteminfo_lnk.php?id=914 
[ 316 ] Robert Rizki Yono, dkk/ To Maega : Jurnal Pengabdian Masyarakat, Vol.4; No.3; Oktober, 2021

Moeljadi., \& Dkk. (2016). kamus besar bahasa indonesia(KBBI V 0.2.1 Beta). https://kbbi.kemdikbud.go.id/

Ngoch, D. T., \& Huan, N. B. (2017). Drama-based role play activities to impact on students' speaking performance. Can Tho University Journal of Science, 07(2017), 91. https://doi.org/10.22144/ctu.jen.2017.054

Ragnarsdóttir, Á. H., \& Porkelsdóttir, R. B. (2012). Creative Learning Through Drama Ása Helga Ragnarsdóttir and Rannveig Björk. Drama Research: International Journal of Drama in Education, 3(1), 1-19.

Sekolah Kita. (n.d.). https://sekolah.data.kemdikbud.go.id/

Soleh dan Huda. (2013). Pengembangan Buku Ajar Drama Berbasis Kesenian Fakultas Pendidikan Bahasa dan Seni IKIP PGRI Madiun. Widyasbastra, 1(2). http://e-journal.unipma.ac.id/index.php/widyabastra/article/view/1153

Suprajitno, S. (2017). Teater Sebagai Media untuk Pengabdian Masyarakat. Jurnal Pengabdian Kepada Masyarakat (Indonesian Journal of Community Engagement), 3(1), 96. https://doi.org/10.22146/jpkm.25757 